Editorial

\title{
Infectious Complications in Liver Transplantation
}

Wasim A. Dar *

Division of Immunology and Organ Transplantation, Department of Surgery, University of Texas at Houston, Health Sciences Center, Houston, USA; E-Mail: wasim.a.dar@uth.tmc.edu

* Correspondence: Wasim A. Dar; E-Mail: wasim.a.dar@uth.tmc.edu

Special Issue: Current State of Evaluation and Management of Infectious Conditions in Liver Transplant Candidates and Recipients

\section{OBM Transplantation}

2018, volume 2 , issue 3

doi:10.21926/obm.transplant.1803021

\section{Keywords}

Liver transplantation; survival; infection
Received: September 03, 2018

Accepted: September 14, 2018

Published: September 29, 2018

Liver disease causing end organ failure is a growing cause of mortality worldwide. It is estimated that up to $25 \%$ of all persons have risk factors for developing liver disease including viral hepatitis, fatty liver disease and alcohol abuse. Unfortunately, for many of these individuals they will develop decompensated liver failure and in most cases the only effective therapy for this end stage disease is liver transplantation.

Fortunately, liver transplantation as a clinical undertaking has achieved high levels of success and as such is regarded as standard of care for the treatment of decompensated liver failure worldwide. But those success rates are still negatively affected by infectious complications. Currently survival rates for liver transplantation are $85-90 \%$ at one year. Infectious complications post liver transplant may account for up to $25-30 \%$ of that mortality. Thus, understanding and improving our management of infectious risk pre and post-transplant could lead to significant improvement in patient outcomes after this complex surgery.

With this in mind, we have commissioned this special issue of OBM-Transplantation to address the current state of infections and their impact on liver transplantation. We have chosen to focus

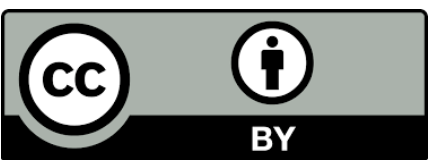

(C) 2018 by the author. This is an open access article distributed under the conditions of the Creative Commons by Attribution License, which permits unrestricted use, distribution, and reproduction in any medium or format, provided the original work is correctly cited. 
on infections pre-transplant which have had significant effects on post-transplant survival such as the viral hepatitides, fungal infections, bacterial infections, and viral reactivation diseases. These compromise the vast majority of infectious risk to the liver transplant recipient. Control of viral hepatitides in the pre- and post-transplant setting has significant effects on patient survival and graft function and the emergence of new anti-virals, particularly for the treatment of Hepatitis $C$ has radically changed the paradigms of treatment.

Fungal infections after liver transplant still represent a considerable risk for infectious morbidity and mortality to the immunosuppressed patient. Diagnosis, prophylaxis, and treatment of these infections is an ever changing field and new therapeutics have broadened the scope of effective therapy but also reflect the increasing danger posed by this class of infectious organisms.

Finally, although viral reactivation diseases such as CMV have been known to affect allograft function after liver transplant, there is still little consensus regarding their monitoring and management in the liver transplant recipient. In particular, there is renewed interest in CMV infection in transplant recipients as the immune response to the virus appears to cause graft injury versus injury from viral replication alone. Thus, achieving the right balance of decreased immunosuppression and treatment of viral replication is critical to the successful control of this and other viral reactivation diseases.

Given of importance of these topics to the field of liver transplantation, we are pleased to present this special issue of OBM-Transplantation. We believe it will provide an important reference for clinicians caring for liver transplant recipients and spur discussion of how to improve treatment modalities to limit infectious complications in this group of patients.

\section{Author Contributions}

The author did all the works.

\section{Competing Interests}

The author has declared that no competing interests exist.

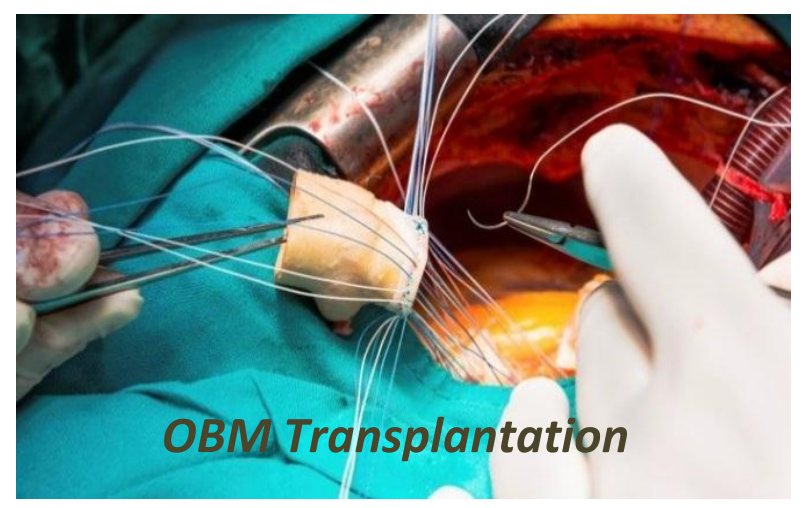

Enjoy OBM Transplantation by:

1. Submitting a manuscript

2. Joining in volunteer reviewer bank

3. Joining Editorial Board

4. Guest editing a special issue

For more details, please visit: http://www.lidsen.com/journals/transplantation 